Commentary

\title{
EU Institutional Politics of Secrecy and Transparency in Foreign Affairs: A Commentary
}

\author{
Emily O’Reilly \\ European Ombudsman, F-67001 Strasbourg, France: E-Mail: eo@ombudsman.europa.eu
}

Submitted: 16 March 2017 | Accepted: 3 May 2017 | Published: 25 September 2017

\begin{abstract}
International diplomacy has long been regarded as the domain of an elite hand-picked few, instructed and groomed in something considered an art form. Both the secrecy and the pomp have their rational place. Political interventions from regime change through to more standard economic and social challenges cue both subtle and dramatic shifts in relationships and alignments and diplomats must rightly handle such situations with great delicacy. Premature or too much public disclosure about diplomatic exchanges could risk undermining the mutual trust and confidence on which the conduct of international relations and negotiations depends. The question of course concerns the determination of what constitutes 'premature' or 'too much' and who decides the point at which public access can or should occur. We have certainly seen a trend towards greater transparency in foreign affairs in recent times, but this will always remain one of the most sensitive areas for national governments and international organisations. Contributors to this publication pose important questions about transparency in the context of foreign affairs at EU level. The question 'How much is enough?' is particularly pertinent. I welcome the exploration of topics of secrecy and transparency in this thematic issue and look forward to further contributions as the theory and practice of the ideas put forward are developed.
\end{abstract}

\section{Keywords}

access to information; diplomacy; EU foreign affairs; EU institutions; negotiations; secrecy; transparency

\section{Issue}

This commentary is part of the issue "EU Institutional Politics of Secrecy and Transparency in Foreign Affairs", edited by Vigjilenca Abazi and Johan Adriaensen (Maastricht University, The Netherlands).

(C) 2017 by the author; licensee Cogitatio (Lisbon, Portugal). This article is licensed under a Creative Commons Attribution 4.0 International License (CC BY).

International diplomacy has long been regarded as the domain of an elite hand-picked few, instructed and groomed in something considered an art form. While essentially a public service it seeks to operate as much as possible in private, free from outside scrutiny.

That considered appropriate for sharing publicly is enunciated usually by Presidents, Prime Ministers or Foreign Secretaries, in a carefully stage-managed environment, the speakers often behind an impressive podium and with an austere or imposing backdrop in order to convey the assumed import of what is being said.

Both the secrecy and the pomp have their rational place. Political interventions from regime change through to more standard economic and social challenges cue both subtle and dramatic shifts in relationships and alignments and diplomats must rightly handle such situations with great delicacy. Very often their work is precisely what keeps both individual states and the wider world safe.

Premature or too much public disclosure about diplomatic exchanges could risk undermining the mutual trust and confidence on which the conduct of international relations and negotiations depends. The question of course concerns the determination of what constitutes 'premature' or 'too much' and who decides the point at which public access can or should occur.

Public access to information laws invariably have an exception applicable to information or documents where disclosure would be likely to harm international relations. Most, including EU Regulation 1049/2001, which governs public access to documents of the EU institutions, are absolute, so not subject to any public interest test. 
Where there is a public interest test, as under the United Kingdom's Freedom of Information Act, the courts have taken a restrictive approach, indicating that the public interest in disclosure must be particularly strong to override the public interest in avoiding harm to international relations. Such rulings are perhaps understandably conservative and restrictive as people outside the diplomacy 'bubble'-including judges-may be understandably reluctant to second guess the insiders.

As European Ombudsman, I am able to consider transparency more widely, as a matter of good administration, balancing the interests of citizens with the genuine needs of the administration for secrecy. I can look beyond the retrospective right to know, which can apply only to documents already in existence, to the arrangements for transparent processes in law-making and prospective negotiations. I can look at the administrative systems in place to give effect to the EU laws and values around transparency and see whether they both align.

I have used my own initiative powers to conduct inquiries into transparency and public participation in the TTIP (Transatlantic Trade and Investment Partnership) negotiations, an initiative which prompted much greater proactive disclosure by the European Commission.

I also examined the transparency of 'trilogues' (the informal meetings of the European Parliament, Council and Commission where the final form of many legislative proposals are brokered).

These are discussed elsewhere in this publication, but from my perspective these were two successful inquiries in which transparency was an issue and international diplomacy was very much in play. In both cases, transparency was advanced through the proactive use of my broad powers to deal with maladministration, making measured and achievable recommendations for improvement, rather than through the narrow prism of Regulation 1049/2001 which can only be a vehicle for disclosing documents already in existence.

The current negotiation around the terms on which the UK will leave the EU is the single most important challenge now facing the EU institutions and where transparency in the conduct of international affairs is at issue. The case for a very high degree of transparency in the public interest is, in my opinion, extremely strong. From the outset it was clear that EU citizens and businesses would have concerns about the potentially far-reaching implications of the outcome of the negotiations and as the negotiations continue we have all witnessed the confusion and often distress caused by the uncertainty around the final outcome. It is impossible to say what those outcomes will be or even when they will be felt, but it is vital to give as much information as possible at the earliest possible time so that individuals, families, and businesses can start making plans for their own futures.

In advance of the triggering of Article 50 of the Treaty by the UK Government, I wrote to the President of the European Commission and to the Secretary-General of the Council, in February and March respectively, urging a proactive approach to the timely public disclosure of relevant information and documents. This, I felt, was important for promoting citizens' trust in the negotiating process, as well as keeping people informed about progress and the issues to be aware of.

I was pleased with the positive responses I received. President Juncker noted, 'These negotiations will be unique....There is no precedent for this process. Therefore, our transparency policy will also be unique and unprecedented'.

In May, the Council issued its Guiding Principles for Transparency in Negotiations under Article 50 TEU, with the stated aim of 'facilitating effective public scrutiny and providing a steady flow of information throughout the negotiations whilst preserving the space to form EU positions and negotiate with the UK'.

This is all very welcome and it may be too early to say whether these fine aspirations will be fulfilled in practice. Nevertheless, one of the opening statements in the Council document is, 'Ensuring that the negotiations are conducted in a transparent manner will be one of the keys of their success'.

For transparency to be identified as a key performance indicator in the context of international negotiations is significant, especially as it comes so soon after the struggles to achieve important, but comparatively modest, improvements in transparency of the TTIP negotiations and conduct of trilogues. It's also true to say that the transparency issue has itself become a preliminary battleground in the negotiations, the commitments on the EU side being in stark contrast to the UK mantra of 'No running commentary'. While it's very early days, it does appear so far that the UK is being forced into a position of being more open than it would like, publishing a series of 'Position' or 'Future Partnership' papers, the content of which has been widely criticised as being vague and unsubstantial. In addition, and as I predicted, important documents are also being leaked, another reason why proactivity is important if the negotiators wish to control their agendas as much as possible.

It's often said that, as a concept, transparency has only one direction of travel. No initiative for less transparency is going to find favour in a modern democracy or with engaged and informed citizens. If that's the case, will this more open approach we are seeing in the Brexit talks be applied in future negotiations conducted by the EU? Or will the 'unique and unprecedented' nature of Brexit be used as justification for an exceptional approach to transparency which is deemed inappropriate when it comes to future negotiations involving international relations? It is clear that transparency-or lack of-is part of the diplomatic political tool-kit of both sides. They are happy to turn on or off the tap as it suits their political aim. While that may in effect be in the public interest, it doesn't necessarily mean that it is done with the public interest exclusively in mind.

Managing the information agenda, in particular the flow of communications which enter the public domain, 
is an important aspect of public relations, be they political, commercial or social.

A proactive approach to transparency means keeping control of that agenda, as opposed to having to react within specified time limits when requests for information are made. Although it is good practice to publish information which helps to explain or contextualise documents or extracts disclosed in response to requests made under a public access regime, it is in fact unusual for public bodies to do so.

The processing of $\mathrm{FOI}$ requests is invariably done in busy offices, often by comparatively junior staff, with senior or political input only coming in at the end of the process, when legal deadlines for compliance are at issue. What is being considered for disclosure will have been defined by the person making the request for information. Withholding information will have to be justified, quite rightly, by reference to legal criteria and, sometimes, to an assessment of where the balance of public interest lies.

We also know particularly in the context of Brexit, that where contentious issues are at stake the flow of official information can be disrupted by leaks. Unauthorised leaks, such as that from the pre-negotiations dinner at 10 Downing Street, usually require a rebuttal or response of some kind and can have a lasting impact on the course of negotiations, the relationship between the parties involved and the public perception of the issues at stake.

These pressures and the loss of control of the information agenda can be avoided by taking a proactive approach to maximum transparency. By seizing the initiative, thinking about and deciding in advance what can and should be published as a matter of public interest, public bodies can win the trust and respect of citizens, businesses and other interested parties, as well as putting themselves on the front foot in terms of public relations and managing the flow of information.

It will be interesting to see how the commitment to proactive transparency in the Brexit negotiations plays out in practice. If the stated principles are not adhered to, I for one will be considering whether I need to intervene in the interests of EU citizens. It may well be that I receive complaints about transparency or other aspects of Brexit from citizens, businesses or concerned interest groups or representative organisations in the EU. As ever, I will not hesitate to use all the powers and resources available to me under the EU Treaties as Ombudsman to pursue the legitimate concerns of others.

Other contributors to this publication pose important questions about transparency in the context of foreign affairs at EU level. The question 'How much is enough?' is particularly pertinent. The protection of legitimate public and private interests is rightly provided for in access to information laws in order to preserve certain important social, economic and democratic principles. Public access to information cannot be unrestricted. Where to draw the line should, in my view, be determined by balancing the public interest in disclosure with the harm to the identified interest which disclosure might reasonably be expected to cause. That can be determined only by exercising judgement on a case by case basis and I do not underestimate the challenge that that can impose. We do not live in a static environment but rather a fluid and dynamic one and the rational judgments of one transparency era may not necessarily survive the demands of the next one.

Privileged, controlled access for the few, such as that won by MEPs in relation to the TTIP negotiations, presents different challenges. Elected representatives are in a position of trust when exercising their democratic responsibilities on behalf of their constituency, but having access to information which some of them may consider should be published because of its wider public interest poses a dilemma. The likelihood is that unilateral action might amount to a breach of a code of conduct or, in some jurisdictions, even a criminal offence. Ultimately these issues engage the conscience of the individual concerned, but there should at least be a means whereby they can officially raise their concerns and put the case for greater transparency.

I welcome the exploration of these topics in this journal and look forward to further contributions as the theory and practice of the ideas put forward are developed. We have certainly seen a trend towards greater transparency in foreign affairs in recent times, but this will always remain one of the most sensitive areas for national governments and international organisations.

\section{Conflict of Interests}

The author declares no conflict of interests.

\section{About the Author}



Emily O'Reilly was elected as the European Ombudsman in July 2013 and took office on 1 October 2013. She was re-elected in December 2014 for a five year mandate. She is an author and former journalist and broadcaster who became Ireland's first female Ombudsman and Information Commissioner in 2003 and in 2007 she was also appointed Commissioner for Environmental Information. Ms O'Reilly is a graduate of University College Dublin with a Degree in European Languages and Literature (1979) and holds a Graduate Diploma in Education from Trinity College Dublin (1980). As former political editor, broadcaster and author, her career attracted significant domestic and international recognition including a Harvard University Fellowship in 1988 and multiple national awards. 